\title{
O LUGAR E O MAPA
}

\author{
Lígia M aria Brochado de Aguiar*
}

\begin{abstract}
RESU M 0 : Este texto é um exercício de imaginação geográfica a partir de uma situação: a de habitar um lugar, ocupar-se dele, cultivá-lo. Explorada por meio de Atlas Escolares M unicipais, esta situação, definida igualmente como geográfica, permite pensar o espaço geográfico como a mediação entre o mundo e o lugar. É a partir do lugar que podemos instaurar o espaço, o espaço que nos convém e responder à pergunta: onde, como e por que estamos. 0 ensino do lugar nas séries iniciais do ensino fundamental refere-se à possibilidade de fazer com que os alunos aprendam a habitar o seu lugar reconhecendo-o como o "espaço do acontecer solidário". Por meio do estudo dos mapas da sua cidade, os alunos apropriam-se de um instrumento de exploração de territórios existenciais e cognitivos que Ihes permite dar visibilidade ao mundo que se realiza no lugar e de um suporte intelectual eficiente que permite visualizar e operar rapidamente as informações.
\end{abstract}

Palavras-chave: Lugar. M apa. Forma. I maginação geográfica.

\section{The PLACE AND THE MAP}

ABST RACT: This text is an exercise of geographical imagination based on a given situation: living in a place, taking care of it and improving it. Explored through Atlas Escolares M unicipais (M unicipal School Atlases), this situation, also defined as a geographical one, allows thinking the geographical space as a mediation between the world and the local place. From this place, we can establish the space, whatever space that may suit us, and answer the questions: where, how and why we are here. Teaching the local place in the first grades of primary school means trying to have our students learn to live in their place, acknowledged as the "space of solidarity happenings". Through the study of maps of their city, students may explore existential and cognitive territories and give visibility to the world that

M estranda em G eografia e diretora de escola da rede pública estadual de ensino de São Paulo. E-mail: platanus@terra.com.br 
"unfolds" in their local place. In addition, it is an efficient intellectual support to visualize and process information quickly.

Key words Place. M ap. Form. G eographical imagination.

\section{Introdução}

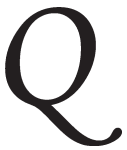

uando se chega a Tecla, pouco se vê da cidade, escondida atrás dos tapumes, das defesas de pano, dos andaimes, das armaduras metálicas, das pontes de madeira suspensas por cabos ou apoiadas em cavaletes, das escadas de corda, dos fardos de juta. À pergunta: Por que a construção de Tecla prolonga-se por tanto tempo? 0 s habitantes, sem deixar de içar baldes, de baixar cabos de ferro, de mover longos pincéis para cima e para baixo, respondem:

- Para que não comece a destruição. - E, questionados se temem que após a retirada dos andaimes a cidade comece a desmoronar e despedaçar-se, acrescentam rapidamente, sussurrando: - N ão só a cidade.

Se, insatisfeito com as respostas, al guém espia através dos cercados, vê guindastes que erguem outros guindastes, armações que revestem outras armações, traves que escoram outras traves.

- Q ual o sentido detanta construção? - pergunta. - Q ual éo objetivo detanta construção senão uma cidade? O nde está o plano quevocês seguem, o projeto?

- M ostraremos assim que terminar a jornada de trabalho; agora não podemos ser interrompidos - respondem.

O trabal ho cessa ao pôr-do-sol. A noite cai sobre os canteiros de obras. É uma noite estrelada.

- Eis o projeto - dizem. (Calvino, 1999, p. 117).

Esta narrativa fictícia é uma breve alegoria de nossa relação com a cidade, com a invenção dos lugares, com o nascimento do mundo a partir de um lugar. Um atlas tem essa qualidade: revela as formas das cidades que ainda não têm formas.

O simples fato de as cidades existirem como forma não basta. D o ponto de vista da geografia é preciso que elas se geografizem, isto é, que a elas sejam atribuídas um conteúdo, uma vida.

Toda forma contém seu próprio desenvolvimento e seu resultado: ela é, portanto, uma função que vai mudando ao longo do tempo. Para que as formas se geografizem é preciso que elas sejam entendidas como relação, processo dialético, que põe em conflito e articula um certo número de coisas, de valores, de situações (eventos). 
Pensar a forma em termos de formação é um exercício que implica a imaginação geográfica: a dinâmica da vida social criando e transformando as formas.

As formas visíveis dos mapas condicionam outras invisíveis porque 0 ato de ver jamais se detém no que é visível. ${ }^{1}$ Como representação do espaço, os mapas não podem esgotar todos os conteúdos dados pelas ações humanas, as quais produzem a imagem desejada do território.

\section{Aslições do lugar e seu aprendizado por intermédio dos mapas}

N osso olhar, ao percorrer os mapas, desfaz os sentidos percebidos e remete a outros sentidos. Assim que percebemos o mundo já estamos realizando a sua construção, porque temos a necessidade de viver para um sentido que não é imanente à vida. Por isso, a construção de Tecla "prolonga-se por tanto tempo".

Podemos ter muitas imagens de um mesmo lugar, mas cada uma delas é uma imagem diferente das outras. Imaginar é justamente construir uma forma à "margem da totalidade", cuja realidade é fugaz e está sempre se desfazendo para voltar a se fazer. As formas e as suas configurações são totalizações que se estão fazendo, portanto, nos mapas temos as "imagens do espaço, ou melhor, do território visto e/ou vivido" (Raffestin, 1993, p. 147).

I maginar é manter o "real à distância". Q uando ensinamos a nossos alunos o lugar por meio dos mapas, é possível desencadear neles a abertura para uma dialética visual que permite restabelecer a horizontalidade do diálogo cotidiano com o espaço-tempo do lugar onde vivem e descobrirem que pertencem a ele.

Para nos apropriarmos do espaço é preciso que antes nos apropriemos de nós mesmos, pois o "nascimento latente do mundo se dá a partir da morada" (Levinas, 1980). No assíduo cuidado pelas coisas da nossa morada, a existência do lugar dá-se de forma plena, acolhedora.

A visibilidade objetiva proporcionada pelo estudo dos mapas do lugar onde nossos alunos vivem deve ser ensinada com o intuito de fazê-los reconhecer seus territórios, aproximá-los do contexto do seu espaço vivido, permitir a desconstrução/reconstrução de cenários, a busca dos significados e dos sentidos das formas da cidade, das relações com outros lugares, com o mundo. 
Sobretudo, nossos alunos precisam imaginar outras malhas urbanas invertendo a relação epistemológica entre o mapa e o lugar: 0 mapa não representa o lugar, mas o lugar que representa o mapa. Assim, nossos alunos apropriam-se do mapa como seu engenho por meio do exercício da imaginação geográfica, transformando a sua visão em apreensão do mundo.

$\mathrm{N}$ essa atividade teórica, na qual se vêem os aspectos sob os quais as coisas aparecem, solidarizamo-nos, comunicamo-nos com o que aparece, chegamos perto da realidade na garantia de seu encontro, de sua convivência.

É impossível falar da distância sem falar do futuro, sem se referir simultaneamente à proximidade e ao presente. As imagens têm potencialidades implícitas, histórias dentro de si. 0 espaço geográfico é a condição da realização dessas histórias e atribui a cada coisa, formas de nossas relações, um lugar.

C ada lugar é uma teia, uma malha de relações intrincadas, processos à procura das formas. A cidade está em todos os lugares, no entanto, quando a encontramos, é difícil fixar no mapa todos os trajetos, todas as trilhas, que a atravessam para ir aos mesmos lugares, ao encontro das formas sonhadas que, por uma ou outra razão, tornaram-se 0 que são, rugosidades (Santos, 1996, p. 113).

Ao mesmo tempo a cidade é redundante, diz tudo o que devemos pensar, o caminho que devemos fazer, o que devemos memorizar. U ma vez percorrido o caminho, ele permanece traçado, evidente, mas a caminhada é, muitas vezes, irrelevante, restringindo nossa capacidade de compreender o espaço geográfico como uma forma de re conhecer o mundo criado pela própria vida, o mundo como lugar em que vivemos com os outros e rodeado pelas coisas, um mundo de cores, sons, odores, sutilezas, poesia, um mundo afetivo e de pessoas, lugares, lembranças, esperanças, conflitos e lutas.

Também o excesso de informações dos aspectos negativos das imagens massificadas da cidade nos faz perder a capacidade de ver e de compreender as geografias dos lugares. Q uanto mais nos entregamos à tarefa de fazer e viver o mundo no lugar em que existimos e vivemos, como condição de nossa liberdade, de nossa vontade de diálogo, tanto mais o lugar, condição do mundo, assume uma existência que nos escapa.

Perdemos o ritmo da convivência com a singularidade do acontecer, das situações. Perdemos o plano, perdemos o projeto, a capaci- 
dade de sonhar, de escolher: Tecla, a cidade, a qual pouco se vê, "escondida atrás dos tapumes, das defesas de pano, dos andaimes, das armaduras metálicas, de pontes de madeiras suspensas por cabos ou apoiadas em cavaletes, das escadas de corda, dos fardos de juta", começa, então, a "desmoronar e despedaçar-se", "não só a cidade", com ela, os seus habitantes.

As imagens estão dentro da experiência, estão incorporadas e re presentadas. A incorporação das imagens implica emoção, moralidade, estética e são estes os significados que engendram as representações. Os mapas são objetos de certeza visual e conceitual, mas são também instrumentos de produção simbólica, produção conceitual cuja verdade está no mundo da vida.

Toda escolha é limitada por uma situação que caracteriza o nosso modo de ser no mundo e compreende um lugar, a configuração territorial tecida de relações flexíveis no próprio cotidiano desse lugar.

A existência já é uma interpretação em si mesma, ela mesma nos ensina 0 que há a aprender. 0 pragmatismo existencial dos habitantes de Tecla dá conta da resposta à pergunta: "Por que a construção de Tecla prolonga-se por tanto tempo?"; "sem deixar de içar baldes, de baixar cabos de ferro, de mover longos pincéis para cima e para baixo", depois de terminada a jornada de trabalho "ao pôr-dosol", a "noite estrelada", o mundo como ele pode ser, "eis o projeto".

O s habitantes de Tecla partilham o mesmo mundo no interior do qual coexistem, mas não fazem parte de Tecla, ao contrário, é a partir deles, dos habitantes, que Tecla pode estabelecer-se, portanto Tecla é o lugar de desenvolvimento próprio, campo de manifestação de seus habitantes. No trabalho de morar, tornam-se habitantes do lugar.

Ao se ocuparem de Tecla, seus habitantes, por um lado, deparam-se com a possibilidade da ação, e, por outro, com as condições de realização dessa ação. Sempre determinados por essas duas possibilidades e, por isso mesmo, os habitantes de Tecla estão amarrados ao projeto de si mesmos.

Ao cultivarem Tecla, seus habitantes podem lançar-se na construção de seus projetos, colocar-se a serviço dos seus sonhos, para fazer do mundo em sua disponibilidade o projeto das suas possíveis ações/atitudes, ensaios de liberdade.

A espacialidade e a temporalidade são condição de entendimento desses projetos, desses ensaios de liberdade, de compreensão do mundo, dos seus propósitos objetivos. Perscrutar com nossos alunos de 
onde vem o senso do caminho a seguir, indagar de onde se determina o objetivo, qual o interesse do objetivo, é aprender junto com eles a permanecer e a morar no interior das coisas, no lugar onde vivemos.

\section{A formação das formas geográficas}

A imagem que vemos dos lugares da cidade é a forma geográfica em sua funcionalidade, isto é, adaptada a um fim que está submetido à intencionalidade das ações humanas, aos interesses de um princípio organizativo da vida em comum dos homens e que marca no espaço do lugar uma configuração territorial e a instrumentalização de nossa relação com o mundo.

Por isso, a geografia é também uma filosofia das técnicas por que nossas ações e nossos projetos são estruturados pelas ferramentas, pelas técnicas, por instrumentos de que dispomos para realizar 0 mundo que desejamos e que nos impele para fora dos limites do nosso lugar em busca de outros mundos.

O s homens são seres de necessidades e é por esta razão que produzem. Além de serem seres de necessidade, os homens, diferentemente dos animais, produzem, inventam ou criam suas próprias necessidades na busca de um sentido para a vida.

Ao produzir, isto é, ao objetivar-se, ao projetar-se de modo prático, material, os homens transformam a natureza. $N$ esse processo, a natureza em si, exterior aos homens, converte-se em natureza humanizada, em natureza para os homens, em espaço geográfico, lugar da sua morada.

Por meio da indústria, a produção ou o trabalho não é só invenção, arte, engenho, poiésis, mas, também, processo, relação histórica real, práxis pela qual os homens exercem sua atividade sobre a natureza, interiorizam a inteligência das coisas e constroem um mundo objetivo.

É no processo produtivo de sua existência que os homens desempenham suas vidas em sociedade e alteram as formas da natureza, totalidade estruturada de elementos naturais, convertendo-as em formas sociais conformadoras de um espaço social.

Este processo se inicia quando os homens trabalham juntos, dividem tarefas com o objetivo comum de alcançar um resultado estabelecido antes mesmo de começarem a trabalhar. 0 ato da produção significa, portanto, o uso consciente das técnicas e dos instrumentos para atingir objetivos definidos. 
Inicialmente, as atividades humanas confundiam-se com os ritmos e os elementos naturais. 0 homem era o próprio instrumento que instrumentalizava as coisas. $\mathrm{N}$ a proximidade dos seres e das coisas, os instrumentos e a técnica não subtraíam a natureza nem suprimiam a participação dos homens na produção. A naturalização dos homens no ato produtivo de sua existência humanizava a natureza ainda mais, permitindo a continuidade, a realização de um plano em harmonia com o conjunto dos elementos naturais.

Aos poucos, o ritmo e as formas da vida e da atividade humanas passaram a ser, cada vez mais, comandados pelos ritmos e pelas formas próprias da produção, e a prática social passou a ser gradativamente o resultado da intermediação do trabalho do homem e a natureza modificada por esse trabalho. É desse modo que o espaço geográfico é criado. A natureza produzida, a natureza se produzindo é a natureza efetiva dos homens.

A evolução constante das técnicas e dos instrumentos de trabaIho, segundo os ritmos e as formas próprias da produção, conduzirá os homens, em diferentes períodos, a novas formas de organização da sua vida em comum, do tempo e das coisas no seu espaço, no lugar onde vivem, a novas formas de pensar e sentir.

Ao movimento de cada lugar particular, cuja historicidade ou realização concreta só pode manifestar-se no espaço geográfico, é acrescentado um movimento real que é dado pela sociedade como um todo, pela sua produção em geral.

$\mathrm{N}$ o interior deste mundo denso e fechado não há lugar para a desordem, para reorganização espontânea, para a poiésis, para a produção-de-si, para a espontaneidade. Cada vez mais fixos, volumosos, estes sistemas de objetos técnicos passam a existir como extensões da própria natureza, incorporam-se a ela como paisagem criada pelos homens.

Assim é que os objetos e as ações no mundo de hoje estão carentes de um discurso, embora já nasçam com um discurso bastante claro e especializado. Por um lado, o valor dos objetos provém da sua eficácia e da sua possibilidade dinâmica de aumentar a produtividade das ações humanas e, por outro lado, as ações humanas perdem a sua espontaneidade, tornam-se pragmáticas, servis, obedientes à racionalidade dos instrumentos.

A ciência aliada ao sistema produtivo ensina-nos a produzir, a fazer alguma coisa, mas não a agir. Para agir precisamos da convivência, da experiência de nós mesmos, da presença do outro, da liberdade, da 
política da qual emergem os conflitos, da qual elegemos novas alianças e a partir da qual podemos construir novas formas socioespaciais.

A técnica e 0 trabalho, por sua vez, não são apenas ações que criam processos organizacionais de produção, são ações que também constroem a vida humana como relação de convívio, de cuidado.

\section{O lugar ea epistemologia da solidariedade}

A invisibilidade tem sido o critério pelo qual temos reduzido 0 espaço geográfico a uma categoria contingente em vez de fundamental para a ação humana. N ão basta apenas ver as coisas, é preciso ver nelas algo, não por um ato de consciência que as nomeie e as objetive, mas na base de uma técnica aprendida de organizar uma situação, uma técnica de ver, um modo de apresentação que é um modo de pensar, portanto de agir: esta técnica de ver se aprende.

0 mundo que vemos não é o mundo, mas um mundo cujo significado e sentido só existem quando tecemos de modo compartilhado a nossa própria vivência de cada coisa, de cada situação. Apenas desse modo podemos dar visibilidade ao mundo, à vida cotidiana como lugar de encontro, de acasos compartilhados, perceber que 0 mundo não existe independentemente de nós. $\mathrm{N}$ ão somos observadores do mundo, participamos dele.

Aprender, portanto, refere-se a uma rede de experiências vivenciadas do conhecimento que adquire validade na convivência e se consolida no exercício da linguagem (da semantização do mundo).

Como sistema de convivência, a força da linguagem advém da sua definição, do acolhimento do seu limite. Produzir outras vibrações nos campos de sentido é propor outra ordem de convivência, outras horizontalidades e verticalidades territorialmente partilhadas e ancoradas em processos solidários de co-presença e co-participação.

0 ensino do lugar por meio dos Atlas Escolares M unicipais pode conduzir nossos alunos à compreensão da cidadania como participação social e política. A apropriação do espaço de representação, das práticas espaciais de representação e da representação do espaço possibilita aos nossos alunos a compreensão da realidade vendo-a de outros pontos de vista, de outros referenciais.

D e um lado, nossos alunos desenvolvem a capacidade de organizar o espaço das funções cognitivas: coleta de informações, 
armazenamento na memória, avaliação, previsão, concepção, decisão etc., adaptando-se ao seu entorno contingente de forma inteligente.

D e outro, ao superar a subjetividade inicial de seus respectivos pontos de vista, graças à construção de uma comunidade de convicções racional mente motivadas, pelas quais se orientam para 0 entendimento, instituem um conjunto de sentidos a partir dos quais também se nutrem para compreender, interpretar e agir sobre 0 mundo.

$\mathrm{N}$ estas passagens, de um reino para outro, dá-se o reencantamento do mundo e das ações para o projeto da rede de relações que se quer instituir. Desse modo, nossos alunos, portadores de processos de aprendizagem (desenvolvimento de capacidades comunicativas), adquirem consciência (capacidade reflexiva), competências comunicativas, o que lhes permite apreender 0 mundo a partir de sua base geográfica, que é o lugar, e de um modo peculiar: na sua relação com ele.

Recebido em abril de 2003 e aprovado em maio de 2003.

\section{N ota}

1. Segundo H. M aturana e F. Varela, em sua obra A árvore do conhecimento (1995, p. 66), não vemos "(...) o espaço do mundo - vivemos nosso campo visual. $\mathrm{N}$ ão vemos as cores do mundo - vivemos nosso espaço cromático. Sem dúvida habitamos um mundo, mas examinando como chegamos a conhecer esse mundo, sempre descobriremos que não podemos separar nossa história de ações de como ele nos parece ser".

\section{Referências bibliográficas}

ALM EID A, R.D. Do desenho ao mapa. São Paulo: Contexto, 2001.

ALM EIDA, R.D.; PASSIN I, E.Y. Espaço geográfico: ensino e representação. São Paulo: Contexto, 1989.

CALVIN O , I. Cidades invisíveis. São Paulo: Companhia das Letras, 1999.

KAH IL, S. P. O mundo no lugar: itinerários para uma geografia da existência. Experimental, São Paulo, n. 4/5, p. 45-56, 1996.

LEVIN AS, E. Totalidade e infinito. Lisboa: Editora 70, 1980. 
M AT URAN A, H .; VARELA, F. A árvore do conhecimento: as bases biológicas do entendimento humano. Campinas: Psy, 1995.

RAFFESTIN , C. Por uma geografia do poder. São Paulo: Ática, 1993.

SAN TOS, M. Espaço do cidadão. São Paulo: N obel, 1987.

SAN TOS, M. Técnica, espaço, tempo, globalização e meio técnico-científico-informacional. São Paulo: H ucitec, 1994.

SAN T O S, M. A natureza do espaço: técnica e tempo, razão e emoção. São Paulo: Hucitec, 1996.

SANTOS, M. Por uma outra globalização. Rio de Janeiro: Record, 2000. 